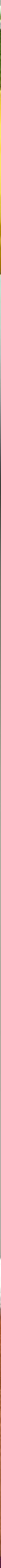

\title{
Corpos que ultrapassam o limite, excedem a fronteira, transbordam de si
}

Bodies that overcome the limit, exceed the border, overflow themselves 


\section{[BEATRIZ FERREIRA PIRES]}

Doutora em Educação. Professora de graduação e pós-graduação do curso de Têxtil e Moda da EACH/USP.

E-mail: beatrizferreirapires@usp.br

[resumo] Foco de inúmeras formas de intervenção que têm como propósito alterar sua aparência, o corpo, que sempre sofreu manipulações com esse intento, adquire na contemporaneidade possibilidades de transformação que em tempos passados eram inconcebiveis. Um dos fatores que contribuem para a diversidade das modificações praticadas hoje é a ligação da área da moda com a área da medicina estética. Tal ligação propicia, àqueles que a desejam, a aproximação do padrão de beleza vigente. Outro fator é o apuro técnico dos modificadores corporais que oferecem, àqueles que desse padrão querem se distanciar, variadas possibilidades. Este artigo versará sobre os que, em ambos os grupos, ultrapassaram o limite, excederam a fronteira, transbordaram de si.

[palavras-chave]

\section{modificação corporal; medicina}

estética, padrão de beleza.

[abstract] As the focus of countless ways of intervention aiming appearance changes, the body has always suffered manipulations with this purpose; in contemporaneity, it acquires transformation possibilities which were once inconceivable. One of the elements contributing to the diversity of modifications practiced nowadays is the bond between the domains of fashion with the domain of aesthetic medicine. Such connection allows an approximation to the current beauty pattern to those whom desire it. Another element is the body modifiers' technical accuracy which offers varied possibilities to those who want to dissociate themselves from this pattern. This article deals with those bodies, in both groups, who have overcome the limit, exceeded the border, overflowed themselves.

[keywords] body modification; aesthetic medicine; beauty pattern. 
Introdução

Na contemporaneidade é crescente o número de conhecimentos, práticas e procedimentos originários das áreas das ciências biológicas e das ciências da saúde que são utilizados pela área da moda e que a ela se mesclam.

0 entrelaçamento dessas áreas coloca em evidência a atual relação que a moda vestivel estabelece com o corpo, na qual não é suficiente que as formas que esse apresenta e/ou que as possiveis alterações que esse sofra, referente aos seus formatos, dimensões, volumes e proporções, sejam resultantes apenas dos elementos que comumente o envolvem, a saber, peças de roupa e acessórios tais como sapatos de salto alto, cintos, chapéus e adornos como anéis etc.

Quando em uso, qualquer uma destas peças interfere no contorno corporal característico do indivíduo. Algumas, dependendo das dimensões, do material com que são confeccionadas e do espaço de tempo em que são utilizadas, alteram, por períodos de maior ou menor duração, a 77 ] textura da pele e a forma do corpo sobre o qual foram utilizadas, mesmo após serem despidas. 0 exemplo clássico de um tipo de peça que realiza tais alterações é o espartilho.

Relação de mão dupla, assim como determinadas peças deixam suas marcas no corpo que as veste, o corpo também deixa suas marcas em determinadas peças que utiliza. Em ambos os casos, os fatores que permitem a impressão de uma superfície na outra são as dimensões e as formas das peças em relação às dimensões e às formas do corpo nelas imerso, a maneira particular com que o corpo do indivíduo que as porta se movimenta e as intensidades depositadas por ele nos gestos, a combinação do tipo de material utilizado na confecção dos produtos e a constituição da parte do corpo na qual esses se sobrepõem.

Um autor que reflete sobre as formas pelas quais as roupas são afetadas pelo corpo e como estas preservam o gestual e as emanações do corpo de quem as veste é Peter Stallybrass. Em seu livro 0 casaco de Marx, o autor parte do fato de que, ao vestir a jaqueta que ganhara da viúva de um amigo próximo, sente-se habitado por ele. Os dois trechos abaixo demonstram a sensibilidade com que Stallybrass discorre sobre esta questão: 
[...] fui habitado por sua presença, fui tomado por ela. Se eu vestia a jaqueta, Allon me vestia. Ele estava lá nos puimentos do cotovelo, puimentos que no jargão técnico da costura são chamados de "memória". Ele estava lá nas manchas que estavam na parte inferior da jaqueta; ele estava lá no cheiro das axilas. Acima de tudo, ele estava lá no cheiro (STALLYBRASS, 2008, p. 10).

Comecei a acreditar que a mágica da roupa está no fato de que ela nos recebe: recebe nosso cheiro, nosso suor; recebe até mesmo nossa forma. E quando nossos pais, os nossos amigos e os nossos amantes morrem, as roupas ainda ficam lá, penduradas em seus armários, sustentando seus gestos ao mesmo tempo confortadores e aterradores, tocando os vivos com os mortos (STALLYBRASS, 2008, p. 10).

Marcas de duração variável, em condições normais, as deixadas nos corpos/peles sobrevivem por menos tempo do que as deixadas nas peças de vestuário, quando as características destas não são alteradas por processos de higienização.

À efemeridade resultante da utilização de um ou de mais indumentos sobrepõe-se a também efemeridade proveniente das alterações realizadas no tegumento, ou seja, no conjunto formado pela pele, cabelos, pelos e unhas, quando estas são feitas com o intuito de aproximar ao máximo 0 próprio corpo do corpo que está na moda.

Os termos "corpo que está na moda" e "corpo da moda" são aqui utilizados para se referir ao corpo que, para se aproximar do padrão de beleza vigente, se submete a diferentes técnicas e procedimentos pertencentes à rentável estrutura disciplinar criada por nossa sociedade.

Nesse contexto, mesmo as alterações corporais feitas por meio de processos cirúrgicos estéticos - tais como implantes não funcionais de silicone, que levam a longos, restritivos e dolorosos períodos de recuperação, e que colocam o corpo em situação de vulnerabilidade em relação a possíveis infecções, reações de rejeição, problemas de cicatrização e alterações de sensibilidade -, embora a princípio, na maioria das vezes, sejam pensadas como definitivas, podem ser transitórias. As próteses podem ser retiradas ou trocadas por outras de diferentes formatos e/ou dimensões.

A remoção ou substituição destas próteses, que não foram implantadas com o intuito de suprir a falta de um membro ou órgão ausente, nem de restaurar uma função comprometida, está vinculada exclusivamente à aparência corporal, ao propósito de adequar o corpo do indivíduo ao corpo da moda e, como tal, a padrões variantes, não duradouros, sujeitos a 
constantes alterações. Entre outras, fazem parte desse grupo as próteses, destinadas seja a corpos femininos, seja a masculinos, de seio, peitoral, glúteo, panturrilha e bíceps.

Para exemplificar tal mutabilidade, podemos nos lembrar dos recentes padrões estipulados em relação ao tamanho ideal dos seios. 0 primeiro padrão corporal prescrito foi o de seios grandes. Muitas mulheres, com o intuito de adequar seus corpos ao modelo, submeteram-se às cirurgias denominadas mamoplastias de aumento. 0 padrão subsequente determinava que o corpo feminino ideal não apresentasse seios tão grandes. Para moldar seus corpos conforme o novo padrão, algumas substituíram as próteses já implantadas por próteses menores, outras fizeram mamoplastia redutora.

Corpo artefato, alvo de incessantes modificações. Ponto focal da cultura farmacopornográfica, apresentada por Paul B. Preciado em seu livro Testo Junkie, na qual as "novas tecnologias do corpo (biotecnologia, cirurgia, endocrinologia, engenharia genética etc.) e da representação (fotografia, cinema, televisão, internet, videogame etc.)" (PRECIAD0, 2018, p. 84-85), atuam de forma determinante para produzir "nosso sujeito contemporâneo e nossa ficção somática" (PRECIADO, 2018, p. 85).

A dinâmica estabelecida entre as áreas da moda, da representação/ exibição e das novas tecnologias do corpo enreda os indivíduos num constante desejar. Ampliadas, pelo rompimento da barreira da pele e pela possibilidade de modificar o corpo a partir de seu interior, as estruturas de controle do corpo estendem seu campo de ação e, consequentemente, de lucro.

\footnotetext{
Se a arquitetura e a ortopedia servem como modelos para entender a relação corpo-poder na sociedade disciplinadora, na sociedade farmacopornográfica os modelos de controle do corpo são microprotéticos: agora, o poder atua por meio de moléculas incorporadas ao nosso sistema imunológico; o silicone toma a forma de seios, neurotransmissores alteram nossas percepções e comportamento; hormônios produzem seus efeitos sistêmicos sobre a fome, o sono. A excitação sexual, a agressividade e a decodificação social da nossa feminilidade e masculinidade (PRECIADO, 2018, p. 86).
}

Nas modificações corporais feitas com o intuito de adequar o próprio corpo ao corpo idealizado pela moda, geralmente a característica de mutabilidade substitui a de perenidade. 
Antes de adentrarmos especificamente no campo das modificações corporais estéticas feitas por meio de técnicas e procedimentos pertencentes às áreas das ciências biológicas e das ciências da saúde, devemos lembrar que o conceito de body modification abrange todo e qualquer tipo de interferência feita no corpo que resulte em sua alteração estética. A gama destas interferências compreende desde corte de cabelos e unhas até procedimentos cirúrgicos altamente invasivos.

Conforme o estadunidense Fakir Musafar (1930-2018) - praticante e profundo conhecedor das técnicas e processos de modificação corporal, xamã, artista e proponente do termo e do movimento primitivos modernos -, embora tais interferências evidenciem-se na materialidade do corpo, elas atuam para além da dimensão carnal. Para Fakir - que baseia as modificações que realizou e que ensinou como diretor e professor da escola Fakir Body Piercing e Branding Intensives, única no mundo que oferece esse tipo de instrução -, os preceitos de nossos ancestrais, primeiros realizadores das práticas de modificação corporal, ensinam que toda e qualquer interferência feita na esfera material do corpo repercute, reflete, se propaga e se reproduz nas suas esferas imateriais.

\section{Conforme Fakir Musafar,}

As marcas feitas no corpo resgatam conhecimentos primordiais e estabelecem uma ligação tátil e visivel entre 0 indivíduo e 0 cosmo. 0 ato de executá-las, que obrigatoriamente envolve a manipulação - logo, a tomada de consciência, por parte do indivíduo, do seu próprio corpo -, faz com que surjam pontes entre o real e 0 imaginário, e entre diferentes tempos e realidades (PIRES, 2005, p. 105-106).

Partindo desse pensamento, mesmo as modificações corporais adquiridas única e exclusivamente com o intuito de alterar a aparência física produzirão alterações nas camadas incorpóreas que envolvem o indivíduo.

\section{Body modification}

A body modification pode ser dividida em dois grandes grupos. 0 primeiro, foco deste artigo e daqui em diante denominado grupo um, é formado por indivíduos que utilizam práticas e técnicas aceitas e incentivadas social e culturalmente para formatar seus corpos conforme o modelo de beleza momentaneamente pré-estabelecido. Os procedimentos utilizados por esse grupo tanto podem ser invasivos como não invasivos. Aos não invasivos correspondem, por exemplo, a utilização de produtos cosméticos 
destinados à pele, aos cabelos e unhas, o corte de cabelos e unhas, a depilação, a manutenção ou raspagem da barba etc. Os possiveis elementos usados nos invasivos, tais como as próteses citadas anteriormente, possuem formas similares às partes que representam e são, invariavelmente, nelas inseridos. Pelo menos até o momento, não se tem conhecimento de alguém que, por exemplo, tenha implantado uma prótese mamária na panturrilha ou vice-versa. Quem supostamente fizesse esse tipo de subversão deixaria de pertencer a esse grupo.

0 objetivo dessas modificações - assemelhar o corpo ao ideal de perfeição em voga - faz com que aqueles a elas submetidos fiquem esteticamente diferentes apenas do que eram antes de sofrerem as intervenções e parecidos com todos os outros que se submeteram aos mesmos procedimentos.

Contornos redesenhados, formas reconfiguradas, superficies (re)texturizadas. Corpos recriados e reproduzidos conforme o modelo ideal. Particularidades homogeneizadas, características igualadas, diferenças amenizadas. Individualidades que se confundem, estéticas que se convertem.

0 segundo grande grupo, daqui em diante denominado grupo dois, é composto por indivíduos que se utilizam de práticas e técnicas que inserem no corpo formas, cores e texturas distintas das pertencentes à espécie humana. Para esses indivíduos, os primitivos modernos, a aquisição de tais marcas corporais não está vinculada a possiveis modismos.

Utilizadas há milênios por nossos ancestrais mais longínquos, estas modificações não apenas distanciam esteticamente o indivíduo que as possui do ideal de beleza vigente, como também da espécie a que pertence. Em sua origem, a aquisição de uma marca corporal, feita por meio de técnicas como tatuagem, piercing e escarificação, estava vinculada às esferas da magia e do sagrado.

Fazendo um parêntese, é importante salientar que, contemporaneamente em nossa sociedade, a aquisição de alguns tipos específicos de modificação corporal, feitos por meio de duas das técnicas utilizadas por membros desse grupo, a tatuagem e o piercing, virou moda e por ela foi incorporada. Entre estas interferências encontram-se, por exemplo, a tatuagem de estrelinhas atrás da orelha, a de nomes próprios de pessoas da familia, namorados e namoradas, inscritos, conforme escolha pessoal, em várias partes do corpo, o piercing de umbigo etc. A aquisição pela moda de práticas de modificação corporal ligadas à tradição cultural de outros povos, ao colocar em foco o uso efêmero de elementos perenes, fez surgir procedimentos e técnicas destinadas ao apagamento, à eliminação dessas inscrições. 
0 método científico, empregado pela medicina estética para a remoção da tatuagem, é o laser. 0 número de sessões necessárias e a eficácia da excisão dependem do tamanho da tatuagem e das cores/tipos de pigmentos utilizados em sua feitura. Além do método científico existem outros que são propagados pela internet. Entre eles destacamos a utilização de lixadeiras. Nesse método, a região da pele na qual a tatuagem está inscrita deverá ser lixada até que o desenho, teoricamente, seja totalmente apagado.

Voltando às origens das marcas corporais, elas, que também podiam desempenhar a função de identificar o indivíduo em relação à sua ascendência - à tribo e/ou à família a que pertencia -, ao seu estado civil e ao ofício que realizava, atuavam como protetoras de malefícios materiais e imateriais e potencializadoras de dons inatos. Como protetoras, resguardavam o indivíduo de ferimentos, doenças, maus sentimentos e pensamentos etc. Como potencializadoras de dons inatos, intensificavam a aptidão natural do indivíduo para realizar determinadas funções. Por exemplo, o caçador da tribo, ao adquirir determinada marca se tornava um caçador melhor, o guerreiro da tribo ao adquirir determinada marca se tornava um guerreiro melhor e assim por diante.

Os desenhos e elementos utilizados na feitura destas interferências corporais tinham como modelo seres de outras espécies e reinos, elementos e forças da natureza, seres mitológicos - a contemporaneidade acrescenta a esses os seres criados pela ficção científica. Ao inserir no corpo tais representações, o indivíduo buscava se apropriar das caracteristicas e qualidades desses seres e elementos criados pelas divindades ou das particularidades e atributos dos seres e elementos que as representavam. Dessa forma, em uma escala de grandeza, as referências que davam origem às inscrições corporais pertenciam a seres que, por possuir determinados atributos, eram entendidos como superiores aos humanos ou a seres percebidos como similares, possuidores de predicados que os humanos não tinham. Como exemplo desse tipo de modificação podemos citar a praticada pelo povo Kaningara. Residentes na Melanésia, nas montanhas de Papua Nova-Guiné na região do rio Sepik, conhecida pelas inundações e pela grande população de crocodilos que abriga, esse povo cultua a ideia de que é descendente do deus crocodilo, criador do mundo. Para adquirirem as caracteristicas e potencialidades desse animal, os homens da tribo, quando na puberdade, submetem-se a um ritual de passagem no qual, por meio da técnica de escarificação, cortes profundos são realizados em seus corpos nas regiões do peito, abdômen e costas. Os feitos ao redor dos mamilos representam os olhos do crocodilo, os realizados no abdômen, as narinas do animal e os inscritos nas costas, suas pernas traseiras e sua cauda. 
Tal processo de modificação corporal segue os quatro preceitos, determinados ancestralmente e listados por Fakir Musafar em Tatuaggi Corpo Spirito, que regem os rituais de passagem. São eles:

Deve ser uma coisa física, deve ser dolorosa, deve haver algum sangue e preferivelmente deixar uma marca' (VALE; JUNO, 2009, p. 11).

A aquisição destas marcas corporais não tem sua origem no desejo da semelhança física e sim na apropriação das faculdades, das capacidades naturais que nesses seres ou elementos se apresentam de maneira mais potente do que no humano.

Isto posto, fica clara a abissal diferença que existe entre as modificações corporais feitas por nossos ancestrais e por aqueles que, na contemporaneidade, por partilharem dos conhecimentos e percepções desses, são adeptos de suas práticas em relação à aquisição de marcas corporais - os chamados modernos primitivos -, daqueles cuja motivação para adquirir tais marcas ou realizar alterações na silhueta está ligada, única e exclusivamente, ao desejo de se assemelhar à materialidade do modelo apresentado como ideal no momento da feitura da intervenção.

Mais recentemente, alguns indivíduos que pertencem ao grupo um passaram a eleger determinados bonecos como modelo para suas intervenções corporais. 0 desejo de adquirir as características de objetos inanimados, produzidos pelo humano para serem a representação material tridimensional da espécie, cujas possíveis qualidades físicas e imateriais são claramente inventadas, arquitetadas e construídas pelo fabricante ou pela imaginação de quem os manipula, insere, na escala de grandeza dos modelos que atuam como matrizes dos atributos a serem adquiridos quando da feitura das alterações corporais, a categoria de modelos cujas faculdades, por serem forjadas, não podem ser transmitidas. Para exemplificar, vamos supor que a eleição de determinado boneco como modelo para a aquisição de uma modificação corporal esteja centrada na qualidade da força. Essa qualidade atribuída a ele, seja pelo molde de sua silhueta, seja pela imaginação de quem o manipula, não existe de fato, é apenas uma representação e, como tal, não pode ser adquirida.

Tal categoria faz surgir uma total inversão na motivação e no fundamento primevo das modificações corporais.

Independentemente do modelo utilizado como propulsor para a aquisição de interferências corporais - ser vivo, mítico, inanimado, elemento da 
natureza ou objeto de qualquer tipo -, os adeptos dessas práticas de ambos os grupos tanto podem adquirir modificações isoladas, independentes umas das outras, provenientes ou não de modelos diversos, feitas ou não por meio de diferentes técnicas e em momentos distintos, cuja disposição espacial está atrelada somente ao gosto e à subjetividade do indivíduo, como podem adquirir marcas com o intuito de transformar detalhadamente sua aparência conforme um único modelo.

A quantidade de intervenções a que um individuo se submete não determina se ele as fez de modo isolado ou segundo um único modelo. 0 que determina tal diferença é a existência ou não de um plano pré-estabelecido.

Desse modo, elegendo apenas um tipo de intervenção, o indivíduo pertencente ao grupo um pode se submeter a vários tipos de cirurgia plástica, como rinoplastia (cirurgia do nariz), mentoplastia (cirurgia do queixo) e otoplastia (cirurgia da orelha), com o propósito de se assemeIhar a vários ou a um único modelo. No caso do nariz ideal pertencer a um indivíduo, o queixo a outro e as orelhas a um terceiro, as modificações serão feitas de forma isolada. Quando todas as partes a serem modificadas se inspiram em um único modelo, o indivíduo possui o que aqui chamaremos de projeto corporal.

Da mesma forma, o indivíduo que pertence ao grupo dois pode, por exemplo, eleger a técnica da tatuagem, em quaisquer de suas várias escolas - old school, new school, pontilhismo, 3D, realista etc. - para inserir em seu corpo desenhos variados, escolhidos conforme o significado que ele atribui a cada um deles, ou utilizar esta técnica para adquirir um conjunto de desenhos que transformem esteticamente seu corpo segundo o modelo que escolheu. No caso da aquisição de desenhos variados, as modificações serão feitas de forma isolada. Quando todos os desenhos a serem tatuados têm como ponto de partida um único modelo, o individuo os adquirirá com o intuito de realizar o que projetou para seu corpo.

\section{Projetos de modificação corporal}

Aqueles que transformam seus corpos a partir de projetos de modificação corporal, normalmente utilizam mais de uma técnica para fazê-lo. Isto não significa que modificações vinculadas a determinados projetos não possam ser realizadas por meio de uma única técnica. Propiciadas pelos procedimentos, instrumentos, aparelhos, pigmentos e matérias-primas atualmente existentes, tais transformações adquirem na contemporaneidade possibilidades que, em tempos passados, eram material e imaterialmente inconcebíveis. 
Enquanto as técnicas e práticas utilizadas pelos membros do grupo um alinham-se à área das ciências médicas, por meio da medicina estética e de áreas afins, as utilizadas pelo grupo dois, embora se desenvolvam por meio de aparatos que foram inovados e, por isso, executam com mais qualidade técnica determinadas funções, mantêm-se fiel às tradições de nossos ancestrais. Como exemplo dos novos aparatos utilizados pelo grupo dois, podemos citar os diferentes modelos de máquina elétrica de tatuagem - a máquina rotativa e a de bobina - e os diferentes tipos de agulha - agulha de traço e agulha de pintura - que, ao permitirem distintas espessuras e diferentes tipos de traço, possibilitam o surgimento de novos estilos de tatuagem.

Entre os individuos pertencentes ao grupo dois que modificaram seus corpos segundo projetos corporais por eles desenvolvidos, um em específico, o canadense Rick Genest (1985-2018), transitou pelo mundo da moda. Genest, conhecido como Zombie Boy, foi levado a atuar em desfiles de moda, ensaios fotográficos e campanhas publicitárias na segunda década desse século pelo editor e diretor de moda ítalo-japonês Nicola Formichetti (1977).

As tatuagens inscritas no corpo de Genest, dentre as quais predominam as que reproduzem seu esqueleto ósseo, produzem no observador a impressão de estar diante do que está abaixo da pele, dos músculos, da carne. Tal impressão é intensificada pelo fato de o desenho de cada osso estar tatuado nas dimensões, localizações e posições que correspondem à própria anatomia de quem os porta. Como, na tatuagem, o formato dos ossos resulta do fundo feito com pigmento de cor preta, o que Genest tem tatuado em seu corpo é o vazio, o oco.

Pele transformada em ossos, o exoesqueleto imagético exibido por Zombie Boy causa estranhamento e, assim como os demais projetos corporais que aqui serão apresentados, remete o observador a novas formas de apreensão, assimilação e compreensão do corpo humano, e o coloca e o circunscreve a uma área situada entre o fascínio e o horror.

Diferentemente de Rick Genest, cujo corpo passou de marginal a modelo, vários outros corpos que foram modificados por meio de diferentes técnicas, conforme um projeto pré-estabelecido, não foram cooptados pela moda e, como tal, continuam habitando obscuras regiões que tangenciam as bordas do local no qual a padronização é regra. Entre esses está o estadunidense Erik Sprague (1972- ).

Na cena moderna das modificações corporais, Sprague, conhecido como The Lizardman, foi um dos pioneiros na elaboração e aquisição de modificações segundo um projeto corporal. 
Com o intuito de se transformar esteticamente em lagarto, Sprague, que começou elaborar seu projeto corporal em 1990, adquiriu as primeiras marcas relativas à execução do projeto, feitas pela técnica de tatuagem, somente quatro anos depois, em 1994. Conforme relata em seu site oficial (SPRAGUE, 2016), até o ano de 2016 ele já havia se submetido a cerca de 650 a 700 horas de tatuagem. Grande parte destas horas foi utilizada para a feitura e o preenchimento de escamas verdes que cobrem todo seu corpo. Entre as modificações a que se submeteu para a realização do projeto estão o lixamento dos quatro dentes incisivos superiores, a bifurcação de língua e o implante subdermal de cinco esferas de teflon acima de cada olho, na região da sobrancelha. 0 alargamento do septo nasal e o alargamento dos lóbulos das orelhas foram feitos independentemente do projeto traçado.

Sprague, que ainda não adquiriu todas as modificações corporais previstas em seu projeto, iniciou sua transformação estética para lagarto no mesmo ano em que terminou seu mestrado em filosofia no Hartwick College (Oneonta, NY). No ano de 1999, abandonou o curso de doutorado, também em filosofia, para se dedicar exclusivamente à carreira de artista performático.

Em relação às interferências corporais que possui e que não se relacionam ao projeto de se assemelhar a um lagarto - como, por exemplo, algumas tatuagens, piercing e alargadores -, Sprague diz não se restringir unicamente ao que nele foi traçado.

A natureza do projeto não é totalmente restritiva aos aspectos puramente reptilianos. Meu corpo ainda é meu e escoIhi incorporar outros elementos que considero desejáveis ${ }^{2}$ (SPRAGUE, 2016).

Como todo projeto de longa execução, o traçado para o corpo de Erik está sujeito a sofrer alterações, substituições, acréscimos e decréscimos, pertinentes à atualização do desejo tanto de quem o projetou como de quem dele desfrutará - que, no caso, é a mesma pessoa.

Se a princípio, em nossa sociedade, somente os corpos modificados segundo projetos corporais criados e desenvolvidos por membros do grupo dois causavam estranhamento, despertavam inquietantes sentimentos, sensações e pensamentos, atualmente alguns corpos transformados conforme projetos cunhados por membros do grupo um também o fazem. E o fazem não por escolherem modelos cuja estética é diferente da humana, mas sim porque, ao modificarem seus corpos, extrapolam a medida, ultrapassam os padrões estabelecidos, excedem os limites. 
Para exemplificar tais modificações, selecionamos entre os membros desse grupo o brasileiro Rodrigo Alves, o estadunidense Justin Jedlica e a sueca Pixee Fox, cuja real identidade não está disponível na web.

Enquanto os dois primeiros elegeram como modelo para suas modificações corporais o boneco Ken, Pixee Fox escolheu as personagens pertencentes ao mundo do desenho animado Jessica Rabbit e Holli Would.

Fazendo um novo parêntese, entre os bonecos os que mais são utilizados como modelo para modificações corporais são a Barbie e o Ken. Ken foi criado no ano de 1961 pela indústria de brinquedos Mattel para ser o namorado da boneca Barbie. Esta, por sua vez, foi criada pela mesma indústria em 1959. Entre as mulheres que a elegeram como modelo estão as ucranianas Valeria Lukyanova, Alina Kovalevskaya, Lolita Richi e Anastasia Shpagina.

Conhecido como Ken humano, Rodrigo Alves, que nasceu na cidade de São Paulo no ano de 1983 e que, atualmente, aos 36 anos, mora e apresenta um programa de televisão de variedades em formato de talk show em Londres, já se submeteu, até o momento, a sessenta cirurgias plásticas e a incontáveis procedimentos estéticos. A primeira parte de seu corpo a ser alterada cirurgicamente, e que se tornou alvo de vários processos operatórios ao longo dos anos, foi o nariz. Em uma das rinoplastias a que se submeteu, realizada no ano de 2016, Rodrigo contraiu uma fasciite necrotizante - infecção bacteriana de rápida propagação e elevado potencial letal que se caracteriza pela necrose da pele, dos tecidos conjuntivos e músculos. A gravidade desta infecção é de tal ordem que, em muitos casos, a única forma de preservar a vida do paciente é amputar o membro contaminado. Após superar essa condição de saúde, e apesar de ser alertado pelos médicos de que os tecidos dessa região, por terem sofrido várias intervenções, já não conseguiriam se recuperar adequadamente, Alves submeteu seu órgão do olfato a uma nova plástica.

Levando em conta apenas esta região do corpo, entre as situações e limitações causadas pelo excesso de cirurgias a que se submeteu, Alves perdeu o olfato e não consegue respirar pelo nariz.

0 projeto corporal de Alves, como seu próprio codinome anuncia, tinha como modelo o boneco Ken. A princípio, assemelhar-se à aparência física desse boneco era seu objetivo. Em determinado momento dessa trajetória, Alves conseguiu tal semelhança. Mas o desejo de possuir um corpo perfeito, totalmente adequado aos padrões de beleza vigentes, fê-lo ultrapassar sua meta. A partir desta ultrapassagem, ele nega ter tido tal projeto e declara que parecer com o boneco Ken nunca foi seu objetivo (ALMEIDA, 2018). 
A constante impermanência do padrão de beleza, que ocorre pela substituição, pelo decréscimo ou acréscimo de novos elementos, faz com que a realização do desejo de possuir um corpo que a ele se iguale seja impossivel. Para exemplificar esta incessante mutação, podemos citar duas pequenas modificações que, recentemente, foram acrescidas ao padrão e que se sustentam segundo a lógica de que a juventude e a saúde estão vinculadas ao que é imaculado, ao que possui perfeita brancura. São elas: $o$ branqueamento dos dentes e o branqueamento da esclera.

Isto posto, é bom termos em mente que as interferências corporais a que Alves e os demais que possuem esse mesmo ideal - ter um corpo semelhante ao corpo da moda - se submetem jamais terão um fim. A cada modificação realizada, outra surgirá como absolutamente indispensável.

É importante perceber que, ao tratarmos das modificações corporais que têm como modelo o padrão de beleza momentaneamente vigente, as expressões "ter um corpo", "possuir um corpo", entram em voga.

Corpo, ser ou ter. Conforme Le Breton (2012), a diferenciação entre corpo e pessoa humana, que começa a despontar com o saber anatômico do século $X V$, quando ocorrem as primeiras dissecações oficiais realizadas nas universidades de Pádua, Veneza e Florença, torna-se mais presente após a publicação, em 1543, do livro de anatomia composto por ilustrações primorosas, De corporis humani fabrica, de Andreas Vesalius. As imagens do corpo fragmentado nele apresentadas rompem a inteireza com que até então o corpo era compreendido.

Anteriormente o corpo não está singularizado do sujeito ao qual empresta um rosto. 0 homem é indissociável de seu corpo, ele ainda não está submetido a esse singular paradoxo de ter um corpo (LE BRETON, 2012, p. 71-72).

É somente por ter existido esta ruptura que as atuais interferências, que fazem do corpo um objeto de (re)design, passivel de ser transformado conforme o desejo de quem o possui, e não de quem o é, são possíveis.

Dentro da dinâmica do constantemente inadequado, uma das mais recentes cirurgias a que Alves se submeteu, que já não se enquadra ao projeto original, foi a de retirada de seus dois pares de costelas flutuantes. Tal cirurgia, altamente invasiva, que tem como objetivo afinar e dar à cintura medidas inumanas, além de causar problemas posturais e respiratórios, por deixar desprotegidos alguns órgãos vitais que estas costelas originalmente envolvem, pode propiciar graves e letais ferimentos. 
Em entrevista dada a Holly Willoughby e Philip Schofield (2018), apresentadores do programa de diversidades da televisão inglesa "This Morning", Alves deixa claro seu desejo de assemelhar seu corpo ao corpo da moda e revela o motivo que o levou a retirar os últimos dois pares de costela:

Todos os meus blazers precisam ser alterados, porque meu tamanho é na verdade 36 de ombros, mas minha cintura era um pouco maior e eu tinha que escolher um blazer maior e ajustá-lo (PERMUY, 2018).

Além da declaração acima, é significativo dizer que, no mesmo programa, Alves ainda faz a seguinte afirmação: "Graças à cirurgia plástica, eu posso me expressar por meio da moda" (PERMUY, 2018), e exibe, dentro de uma redoma de vidro, os dois pares de costela que tirou (figura 1).

Figuras 1: Rodrigo Alves - Ken Humano

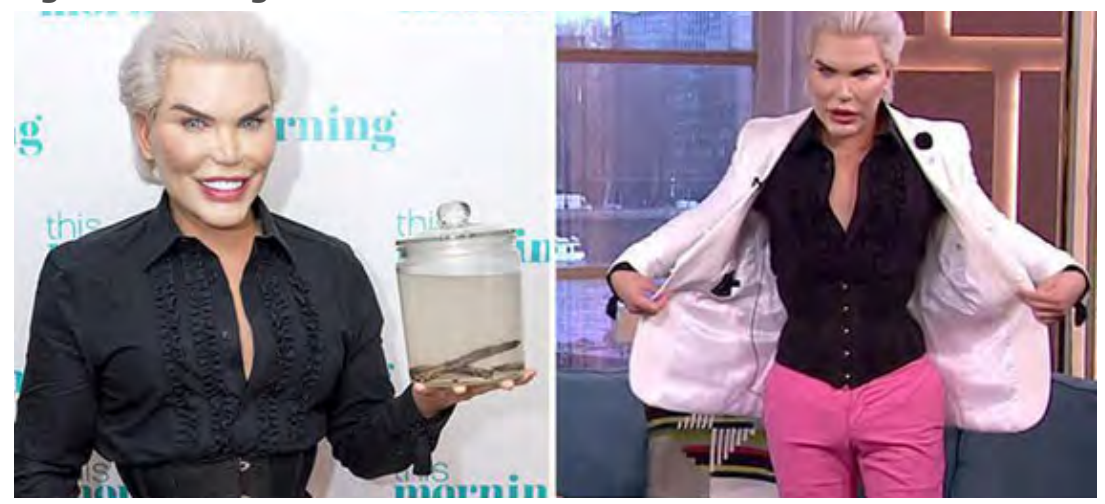

Fonte: PERMUY, Pedro. Ken Humano exibe costelas retiradas do próprio corpo após plástica. Gazeta Online, 25 jan. 2018. Divirta-se. Disponível em: https://www.gazetaonline. com.br/entretenimento/famosos/2018/01/ken-humano-exibe-costelas-retiradas-doproprio-corpo-apos-plastica-1014116464.html. Acesso em: 13 mar. 2019.

Corpo modificado para se assemelhar a um boneco. Corpo modificado para adequar-se à indumentária que quer vestir. À total inversão na motivação e no fundamento primevo das transformações corporais, acrescenta-se a total inversão na relação primeva entre indivíduo e produto.

Outro que tinha como projeto corporal se transformar no Ken humano é Justin Jedlica. Nascido em Nova York no ano de 1980, Jedlica, que também tem a rinoplastia como a primeira cirurgia plástica a que se submeteu, fez mais de cem procedimentos cosméticos e intervenções cirúrgicas (JEDLICA, 2017). Entre elas, além das cinco cirurgias de nariz, ele se submeteu ao aumento labial e das bochechas, à elevação das sobrancelhas e ao implante das seguintes próteses: de bíceps, triceps, peitoral, panturrilha, coxas e glúteos. 
Em seu site, Jedlica se apresenta como consultor para procedimentos estéticos e design de próteses de silicone personalizadas. Ele, que garante sigilo aos que o procurarem e pensa que cada indivíduo deve seguir seu próprio ideal de beleza, oferece consultoria sobre tais intervenções baseado na experiência que adquiriu ao ter-se submetido a inúmeras cirurgias eletivas.

\footnotetext{
Seu corpo é seu templo, e Justin está aqui para atuar como arquiteto - seu especialista em design. De seus muitos anos de experiência pessoal dentro da arena da modificação do corpo, Justin agora mantém um arsenal dos especialistas médicos mais qualificados, credenciados, cosméticos que agem com a máxima discrição. Através de nosso discreto encaminhamento, serviços de consultoria e coordenação, Justin e sua equipe garantem a rota mais direta e abrangente para alcançar o resultado desejado (seja sutil ou mais extremo) ${ }^{3}$ (JEDLICA, 2017).
}

Em sua mais recente cirurgia, Jedlica implantou próteses de silicone nas costas (figura 2). As próteses - que foram por ele desenhadas e artesanalmente fabricadas para garantir que, ao serem implantadas, não distanciassem sua silhueta da estética do corpo de Ken - têm o intuito de transmitir a impressão de que ele possui asas. A mescla de referências, boneco e anjo, não o faz abrir mão de Ken.

\section{Figura 2: Justin Jedlica - Ken Humano}

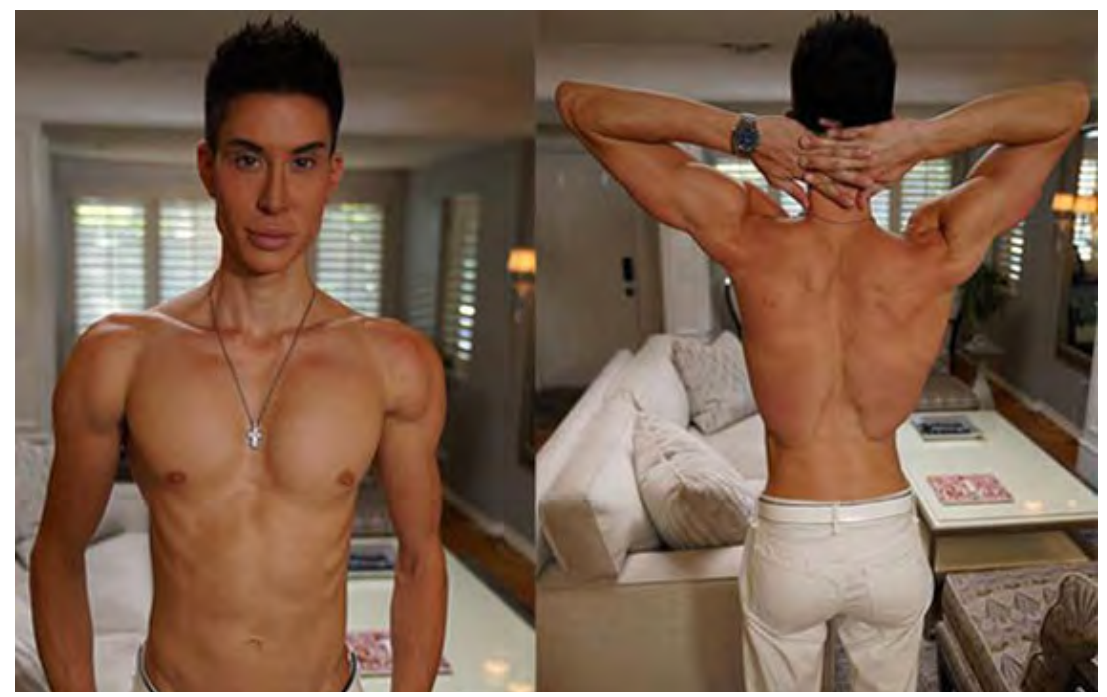

Fonte: BARCROFT MEDIA. Surgery obsessed. 2017. 2 fotografias, color. Disponivel em: https://www.dailystar.co.uk/real-life/654219/Human-Ken-Doll-Justin-Jedlica-beforeplastic-surgery. Acesso em: 13 mar. 2019.

Embora tenha se preocupado em adaptar a prótese que representa as asas à silhueta moldada segundo o corpo de Ken, Jedlica, em 
declarações recentes (GUEDES, 2012), disse que nunca teve o boneco como modelo e que tal codinome foi a ele associado como forma de explicitar a quantidade de material sintético que tem no corpo. $\mathrm{Na}$ sequência da declaração, diz que seu ideal é ter, em cada momento da vida, a aparência mais perfeita possivel.

Ken e Jedlica, boneco e humano. Corpos compostos total ou parcialmente de matérias inorgânicas e plásticas, moldáveis segundo o desejo de quem o produz ou o possui e as possibilidades técnicas do momento.

Paralelamente às alterações corporais que adquiriu, Jedlica lançou uma linha de camisetas estampadas como o desenho de seu tronco nu segurando uma seringa ao lado da frase "Plastic makes perfect". A frase reforça sua inclinação para alterar sua silhueta por meio de procedimentos médicos cirúrgicos.

Diferentemente de Alves e de Jedlica, que escolheram como modelo para suas transformações corporais um boneco inerte de plástico, a modelo Pixee Fox, que atualmente reside nos Estados Unidos, escolheu duas personagens que se expressam por meio da linguagem de desenho de animação. A primeira, inspirada nas atrizes Veronica Lake e Rita Hayworth, é a 9I J Jessica Rabbit do filme, dirigido por Robert Lee Zemeckis no ano de 1988, Uma cilada para Roger Rabbit. A segunda é Holli Would, do filme dirigido por Ralph Bakshi no ano de 1992, Mundo proibido.

Enquanto todo e qualquer contexto, toda e qualquer sequência de atos e de acontecimentos que envolvem um boneco têm seu enredo atrelado à imaginação de quem, no momento da ação, se entretém ao manipulá-lo, e todo e qualquer movimento por ele realizado depende materialmente da manipulação expressa desse mesmo indivíduo, o contexto, a sequência de atos e de acontecimentos nos quais um personagem de desenho de animação se insere, também eles inventados por um humano, independem do desejo de quem, no momento da exibição, dele se ocupa. Por serem animados os desenhos das personagens que inspiram Pixee Fox, transmitem a ideia de terem alma, de terem vida própria e, como tal, de serem capazes de ter seus próprios desejos e realizar seus próprios movimentos.

Similares, os corpos de Jessica Rabbit e de Holli Would foram desenhados com cores, texturas, proporções e volumes considerados sexies tanto pelo imaginário de seus autores como pelo imaginário do público que ambos queriam atingir.

Embora ambos os modelos - boneco e personagem de desenho animado - resultem da imaginação humana, o tipo escolhido por Pixee Fox evoca a ideia de autonomia e, como tal, expõe ao espectador, além das caracteristicas físicas, qualidades e faculdades outras. 
Em comum com Alves, Pixee Fox (figura 3) tem, além do apreço pela modificação corporal em busca do corpo perfeito, o fato de também ter-se submetido à cirurgia para retirada dos últimos pares de costela - no caso dela, dos três últimos. Além desta interferência, ela se submeteu a quatro rinoplastias, preenchimento dos lábios e das bochechas, alteração do formato das sobrancelhas, gluteoplastia de aumento, duas lipoaspirações, quatro mamoplastias de aumento e a vários outros procedimentos (FERNANDES, 2015).

Figuras 3: Pixee Fox

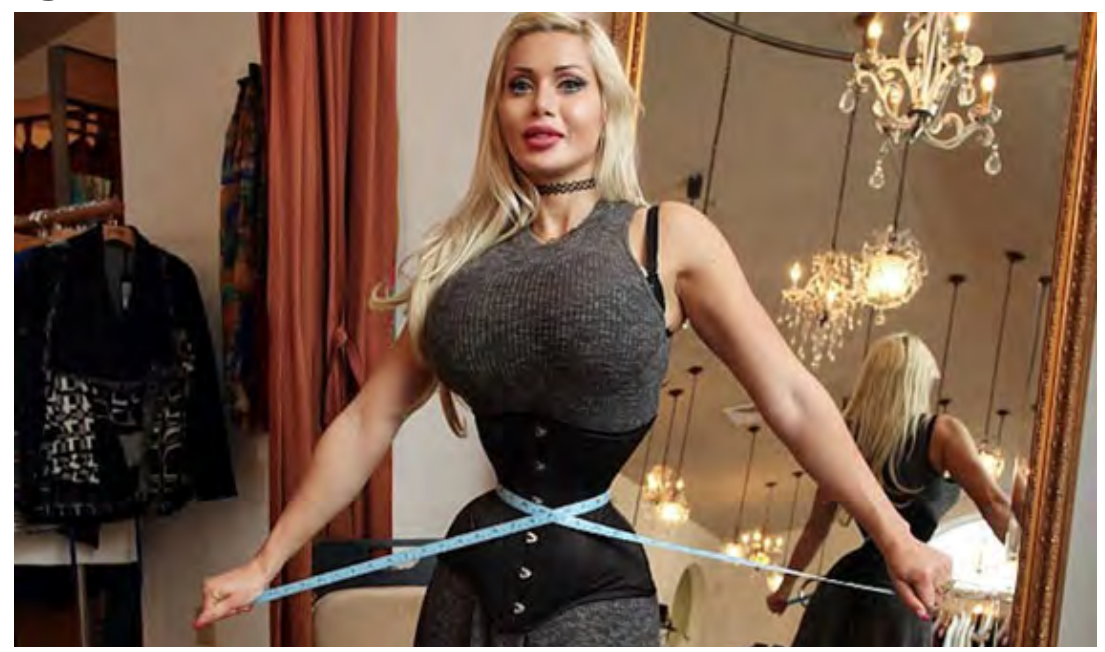

Fonte: THE TALKO. Pixee Fox: 12 Facts About The Living Doll. 2015. Disponivel em: https:// www.thetalko.com/pixee-fox-12-facts-about-the-living-doll/. Acesso em: 13 mar. 2019/

Alguns sites veiculam fotos e vídeos que divulgam uma suposta relação amorosa entre ela e o Ken humano Justin Jedlica. Neles, entre as fotos publicadas os dois aparecem vestidos com as camisetas pertencentes à coleção lançada por ele (BALSON, 2016). Notícias fabricadas sobre corpos também fabricados. Simulacros que se sobrepõem.

Disciplinado, o corpo almeja a imagem e o orgânico acolhe em si o inanimado.

0 corpo já não habita os espaços disciplinadores: está habitado por eles. A estrutura orgânica e biomolecular do corpo é o último esconderijo desses sistemas biopolíticos de controle. Esse momento contém todo o horror e a exaltação da potência politica do corpo (PRECIADO, 2018, p. 86).

As modificações corporais adquiridas por Alves, Jedlica e Pixee Fox mostram indivíduos que arquitetaram projetos e alteraram seus corpos por meio de procedimentos provenientes da área médica, tendo como único propósito assemelhá-los ao corpo da moda. 0 número de intervenções a 
que cada um deles se submeteu e o fato de que, algumas vezes, a última interferência desfaz o que a penúltima havia feito, evidencia a fugacidade com que os modelos de beleza são substituídos e a quantidade de procedimentos destinados a cada parte do corpo. Como reflexo dessas duas circunstâncias, seus corpos apresentam mutáveis configurações. Essas, por excederem as formas, dimensões e volumes próprios do humano, despertam no observador sensações semelhantes às que surgem quando da observação dos corpos modificados pertencentes ao grupo dois.

\section{Conclusão}

As modificações corporais feitas por meio de intervenções médico-cirúrgicas altamente invasivas, única e exclusivamente com o intuito de assemelhar o corpo que se tem ao corpo da moda, é uma prática disciplinar utilizada pela cultura farmacopornográfica que, conforme Preciado (2018), começa a se desenvolver em meados do século XX. Para além do conhecimento científico, da habilidade e destreza dos profissionais que as executam, dos aparelhos e instrumentos que as possibilitam, dos materiais e substâncias que são no corpo aplicados, injetados ou inseridos, tais procedimentos só puderam ser implantados após um longo processo estabelecido culturalmente que associa o ideal momentâneo de beleza ao 93 conceito vigente de saúde perfeita.

Tal associação, ao incluir o critério estético no ofício médico, abre precedente para que o caminho seja trilhado no sentido contrário, e passa a admitir que critérios médicos sejam utilizados na área da moda.

Se em tempos passados a medicina separou o corpo da pessoa humana, em tempos atuais ela separou o corpo da matéria orgânica. Mescladas e não mais discerniveis, a vinculação destas duas áreas de conhecimento promete possibilidades inimagináveis.

Recebido: 15-10-2018

Aprovado: 27-11-2018

\footnotetext{
NOTAS

1 Tradução da autora para: "Deve essere una cosa fisica, deve essere dolorosa, ci deve essere del sangue e preferibilmente lasciare um segno".

${ }^{2}$ Tradução nossa para: "The nature of the project is not wholly restrictive to purely reptilian aspects. My body is still mine and I have chosen to incorporate other elements I find desirable".

${ }^{3}$ Tradução nossa para: "Your body is your temple, and Justin is here to act as the architect--your design specialist. From his many years of personal experience within the body modification arena, Justin now retains an arsenal of the most skilled, accredited, cosmetic medical specialists who act with the utmost discretion. Through our discreet referral, consultative and coordinator services, Justin and his team assure you the most direct and comprehensive route to achieve your desired result (whether subtle or more extreme)".
} 


\section{REFERÊNCIAS}

ALMEIDA, João. Ken Humano retira costelas e mostra os ossos na TV. TV Foco, 26 jan. 2018. Disponivel em: https://www.otvfoco.com.br/ken-humano-retira-costelas-e-mostra-os-ossos-na-tv/. Acesso em: 3 out. 2018.

BALSON, John. Pixee Fox and Justin Jedlica are the real life Barbie and Ken. Barcroft TV, 24 ago. 2016. Disponivel em: http://www.barcroft.tv/pixee-fox-justin-jedlica-plastic-surgery-las-vegas. Acesso em: 9 out. 2018.

FERNANDES, Thamyris. Pixee Fox: ela tirou 6 costelas para parecer desenho animado. Área de mulher, 2 dez. 2015. Disponivel em: https://areademulher.r7.com/curiosidades/pixee-fox-ela-tirou6-costelas-para-parecer-desenho-animado/. Acesso em: 13 mar. 2019.

GUEDES, Bernardo. Entrevista Exclusiva com Justin Jedlica. Kens Klub. 4 nov. 2012. Disponivel em: http://kensklub.blogspot.com/2012/11/entrevista-exclusiva-com-justin-jedlica.html. Acesso em: 9 out. 2018

JEDLICA, Justin. Site oficial, 2017. Disponivel em: http://justinjedlica.com/. Acesso em: 9 out. 2018.

JEDLICA, Justin. Justin Jedlica is an individual who works with the most discerning patients, those who will accept nothing but the best quality medical care. Justin Jedlica, 2017. Consulting. Disponivel em: http://justinjedlica.com/consulting.html. Acesso em: 9 out. 2018.

LE BRETON, David. Antropologia do corpo e modernidade. 2. ed. São Paulo: Vozes, 2012.

PERMUY, Pedro. Ken Humano exibe costelas retiradas do próprio corpo após plástica.

Gazeta Online, 25 jan. 2018. Divirta-se. Disponivel em: https://www.gazetaonline.com.br/ entretenimento/famosos/2018/01/ken-humano-exibe-costelas-retiradas-do-proprio-corpo-aposplastica-1014116464.html. Acesso em: 13 mar. 2019.

PIRES, Beatriz Ferreira. 0 corpo como suporte da arte - piercing, implante, escarificação, tatuagem. São Paulo: SENAC, 2005.

PRECIADO, Paul B. Testo Junkie: sexo, drogas e biopolítica na era farmacopornográfica. São Paulo: n-1 edições, 2018.

SPRAGUE, Erik. The Lizardman Frequently Asked Questions - Version 2.6. The Lizard Man, nov. 2016. Disponivel em: http://www.thelizardman.com/faq.html. Acesso em: 13 mar. 2019.

STALLYBRASS, Peter. 0 casaco de Marx: roupas, memórias, dor. 3. ed. Belo Horizonte: Autêntica, 2008.

VALE, V.; JUNO, A. Tatuaggi, Corpo, Spirito. Milão: Apogeo, 1994.

WILLOUGHBY, Holly; SCHOFIELD, Philip. Has had four ribs removed in his quest for the perfect body. This Morning, 23 jan. 2018. Disponivel em: https://www.youtube.com/watch?v=zBGxPuqCOIY. Acesso em: 3 out. 2018. 